\title{
1 Bifunctional N-doped graphene Ti and Co nanocomposites for the oxygen reduction and evolution reactions
} \\ J.M. Luque-Centeno ${ }^{1,2}$, M.V. Martínez-Huerta ${ }^{1 *}$, D. Sebastián ${ }^{2 *}$, G. Lemes ${ }^{2,3}$, E. Pastor ${ }^{3}$, \\ M.J. Lázaro* \\ 5 \\ 1 Instituto de Catálisis y Petroleoquímica, CSIC, Marie Curie 2, 28049 Madrid, Spain \\ 2 Instituto de Carboquímica, CSIC, Miguel Luesma Castán 4, 50018 Zaragoza, Spain \\ 3 Departamento de Química, Instituto Universitario de Materiales y Nanotecnología (IMN), Universidad de La Laguna \\ (ULL), Apartado 456, 38200 La Laguna, Tenerife, Spain \\ *Correspondence: mmartinez@icp.csic.es; dsebastian@icb.csic.es; $\underline{\text { mlazaro@icb.csic.es }}$
}

Abstract: Developing efficient, durable, and low cost catalysts based on earth-abundant elements for the oxygen reduction reaction (ORR) and oxygen evolution reaction (OER) is essential for renewable energy conversion and energy storage devices. We report herein a simple one-pot procedure for the synthesis of non-precious metals $\mathrm{N}$-doped graphene composites employing urea as nitrogen source, and their application as bifunctional catalysts for both the ORR and OER in alkaline environment. In this study, the effects of the addition of $\mathrm{Ti}$ and $\mathrm{Co}$ on the structure and performance of the $\mathrm{N}$-doped graphene composites are investigated. The incorporation of $\mathrm{Ti}$ leads to a composite with both anatase and rutile $\mathrm{TiO}_{2}$ crystalline phases as well as $\mathrm{Ti}^{3+}$ species stabilized upon hybridization with $\mathrm{N}$-doped reduced graphene oxide. The ORR onset potential for the Ti-based composite is $0.85 \mathrm{~V}$ (vs. RHE) and the number of electrons transferred is 3.5, showing superior stability than Pt/C after accelerated potential cycling in alkaline solution. However, this composite shows low activity and stability for the OER. On the other hand, the composite consisting of metallic $\mathrm{Co}$ and $\mathrm{CO}_{3} \mathrm{O}_{4}$ nanocrystals grown on $\mathrm{N}$-doped reduced graphene oxide exhibits the best performance as bifunctional catalyst, with ORR and OER onset potentials of $0.95 \mathrm{~V}$ and $1.51 \mathrm{~V}$ (Vs. RHE), respectively, and a number of electrons transferred of 3.6 (ORR). The results reveal the presence of important structural features such as metallic $\mathrm{Co}$ as the predominant crystalline component, amorphous $\mathrm{CO}_{3} \mathrm{O}_{4}$ phase and the coordination of $\mathrm{Co}-\mathrm{N}$-doped graphene. All of them seem to be fundamental for the high activity and stability towards ORR and OER. 
Oxygen reduction (ORR) and evolution (OER) reactions are undoubtedly the most important electrochemical reactions associated with energy conversion and storage technologies, such as fuel cells or water electrolyzers, and the combination of both systems: unitized regenerative fuel cells (URFCs) [1, 2]. However, the sluggish kinetics of these reactions in acid environment at low temperature requires a large quantity of precious metals (e.g. Pt, Ir or Ru) to enhance reaction activity and durability [3-8]. The utilization of anion exchange membranes presents several potential advantages compared to its acidic Nafion-based counterpart, including improved kinetics of electrochemical reactions, materials stability, and easy water management [9-12]. Therefore, anion exchange membrane fuel cells and electrolyzers may hold great potential in the near future, providing an opportunity to use a host of non-platinum group metal catalysts [13]. Furthermore, anion exchange membranes unitized regenerative fuel cells (AEM-URFCs) have attracted attention in recent years because they involve interconversions between $\mathrm{H}_{2}, \mathrm{O}_{2}$, and $\mathrm{H}_{2} \mathrm{O}$ in a single system $[14,15]$. AEM-URFCS possess high specific energy, enjoy economies-of-scale advantages, are modular in nature, and require only environmentally benign and inexpensive reactants. This electrochemical system constitutes a promising technology for large-scale energy storage, which is extremely necessary when renewable and intermittent energy sources are used.

The rational design of superb catalysts with earth-abundant elements, superior reactivity, and sufficient stability under operating conditions, which are also bifunctional catalysts for both ORR and OER, is of urgent importance for the development of oxygen electrochemistry-involved devices [16]. Typically, good catalysts for ORR tend to exhibit poor OER performance and vice versa. Among all the nonprecious metal catalysts formulations studied, carbon-based catalysts hold the greatest promise to replace precious metals in the future due to their low-cost [1, 17-19]. In particular, N-doped carbon nanocomposites and earth-abundant transition metals have demonstrated remarkably improved catalytic activity and stability in alkaline electrolyte $[1,16]$. The electrocatalytic active sites are formed by the coordination of metal-nitrogen-carbon (Me-N-C) species ( $\mathrm{Me}=\mathrm{Co}, \mathrm{Fe}, \mathrm{Ni}, \mathrm{Mn}$, etc.), where the morphology of carbon matrix has a determining role on activity (e.g. nanotubes, graphene) [17, 20-22]. Depending on the nanocarbon structure and transition metal, a synergetic effect towards enhanced performances can be observed. Synthesis conditions like the number of heat treatments in nitrogen-rich atmosphere or their temperature, undoubtedly influence the physico-chemical features of the electrocatalysts and, in turn, the electroactivity [23-25]. The interaction between $d$-electrons of metal moieties and $\pi$-electrons in the carbon basal plane modify the local electronic 61 structure of the active sites, leading to a favorable adsorption of intermediates and a higher activity [16, 2629].

Among these materials, cobalt-based $\mathrm{N}$-doped carbon catalysts have attracted particular attention due to their low cost, high abundance and appropriate features to act as bifunctional catalysts for both the ORR and the OER [17, 23, 30-34]. However, a good understanding of the structure-activity relationship of these composites for ORR and OER under harsh operating conditions is still to be achieved. In contrast, only a few 
research works have been reported with the application of titanium species as bifunctional electrocatalysts $[7,8,35]$. In these works, platinum is the active site, which is supported on TiN, TiCN or TiC materials. Furthermore, the low intrinsic conductivity and poor reactivity of $\mathrm{TiO}_{2}$ are believed to hamper the efficient application of this material in electrocatalytic applications that require fast electron transport [36].

Herein, a simple one-pot method was investigated to synthesize nanocomposites of $\mathrm{Co}$ and Ti with $\mathrm{N}$-doped graphene using urea as nitrogen source. Both composites have been characterized and tested as bifunctional catalysts for both the ORR and the OER under alkaline conditions. Additionally, accelerated durability tests have been performed in order to investigate the behavior of the systems under harsh conditions of applied potential.

\section{Experimental}

\subsection{Chemicals and reagents}

Graphite powder $(>99.8 \%$ purity, particle size $<20 \mu \mathrm{m}), \mathrm{KMnO}_{4}(>99.8 \%$ purity), cobalt (II) chloride hexahydrate $\left(\mathrm{CoCl}_{2} \cdot\left(\mathrm{H}_{2} \mathrm{O}\right)_{6},>97 \%\right.$ purity), urea $\left(\mathrm{CH}_{4} \mathrm{~N}_{2} \mathrm{O},>98 \%\right.$ purity) and sodium hydroxide $(\mathrm{NaOH}, 99.99 \%)$ were obtained from Sigma-Aldrich. Concentrated $\mathrm{H}_{2} \mathrm{SO}_{4}(96 \%)$ and $\mathrm{H}_{2} \mathrm{O}_{2}(30 \% \mathrm{v} / \mathrm{v})$ were provided by Merck and Foret, respectively. Titanium (IV) n-butoxide ( $\mathrm{Ti}\left[\mathrm{O}\left(\mathrm{CH}_{2}\right)_{3} \mathrm{CH}_{3}\right]_{4},>99 \%$ purity) and iridium (IV) oxide (IrO 99\% purity) were purchased from Alfa Aesar. Ethanol Absolute $\left(\mathrm{CH}_{3} \mathrm{CH}_{2} \mathrm{OH}, 96 \%\right.$ purity) was acquired from Panreac. The commercial Pt/C catalyst with 20 wt.\% Pt was purchased from the Johnson Matthey Corp. All the chemicals were used as received without further purification. Ultrapure water $(18.2 \mathrm{M} \Omega \mathrm{cm})$ through Millipore system (Milli-Q ${ }^{\circledast}$ ) was used in all the experiments.

\subsection{Composites synthesis}

89 Graphene oxide (GO) was synthetized from the graphite powder by a modified Hummer's method [37, 38]. 90 For the synthesis of the composites, $0.4 \mathrm{~g}$ of $\mathrm{GO}$ was dispersed in ethanol ( $3 \mathrm{~mL})$ by ultrasonication for $3 \mathrm{~h}$. 91 Then, an appropriate amount of metal precursor was added slowly to the solution, which was stirred for 30 $\mathrm{min}$ and sonicated for additional $30 \mathrm{~min}$. After that, $2 \mathrm{~g}$ of urea was added to the mixture solution. Metal to urea molar ratio was kept at 1:20. This solution was stirred until urea was completely solubilized, which was

94 left overnight to complete the gel formation. Finally, the gel was transferred to a quartz tubular reactor, heated at rate of $3^{\circ} \mathrm{C} \cdot \mathrm{min}^{-1}$ and annealed at $800^{\circ} \mathrm{C}$ for 2 hours under $\mathrm{N}_{2}$ atmosphere. The obtained material was thoroughly washed with water and acetone in order to remove impurities. The as-obtained composites were labeled as $\mathrm{Ti} / \mathrm{NrGO}$ and $\mathrm{Co} / \mathrm{NrGO}$. 
101 amount was determined by inductively coupled plasma - optical emission spectroscopy (ICP-OES) using a SPECTROBLUE AMETEK spectrometer.

103 The crystalline structure of the materials was determined by X-ray diffraction (XRD), using a Bruker D8

104 Advance polycrystalline powder X-ray diffractometer with a Cu Ka source. Chemical surface composition was 105 determined by X-ray photoelectron spectroscopy (XPS) with a OMICRON ESCA+ spectrometer with dual x-ray 106 source $(\mathrm{MgK} \alpha=1253.6 \mathrm{eV}$, AIK $\alpha=1486.6 \mathrm{eV})$. CasaXPS software was used for obtaining atomic percentage 107 compositions, using Gauss-Lorentz equations with the Shirley-type background. A 70\%/30\% 108 Gaussian/Lorentzian line shape was used to evaluate peaks position and areas of the high-resolution 109 spectra. Accurate binding energies $( \pm 0.2 \mathrm{eV})$ were determined by referencing to the $\mathrm{C} 1 \mathrm{~s}$ peak at $284.6 \mathrm{eV}$.

110 Raman spectra were recorded at room temperature with a Renishaw in Via Raman Microscope 111 spectrometer equipped with a laser beam emitting at $532 \mathrm{~nm}$ and $5 \mathrm{~mW}$ output power. A HRTEM JEOL 112 2100F operating at an accelerating voltage of $200 \mathrm{kV}$ was used to obtain transmission electronic microscope 113 (TEM) images, which allows evaluating the morphology and the metallic nanoparticles size in the catalysts. 114 The particle size distribution of each catalyst was calculated using frequency count method of Origin 115 program measuring the diameter of at least 200 metallic nanoparticles. Scanning electron microscope (SEM) 116 images were recorded using a Hitachi instrument, model TM-1000.

\subsection{Electrochemical characterization}

119 All electrochemical measurements were performed at room temperature in a three-electrode system 120 controlled by a potentiostat/galvanostat AUTOLAB PGSTAT302N. A reversible hydrogen electrode (RHE) in 121 the supporting electrolyte was used as reference electrode while a high surface glassy-carbon rod was 122 employed as counter electrode. For the working electrode, a rotating ring disk electrode (RRDE) with a Pt 123 ring and a glassy carbon disk of $5 \mathrm{~mm}$ of diameter $\left(0.196 \mathrm{~cm}^{2}\right)$ was used. The working electrode was 124 prepared by depositing $30 \mu \mathrm{L}$ of catalytic ink onto the glassy carbon area. This catalyst ink was prepared by 125 sonicating $4 \mathrm{mg}$ of catalyst with $15 \mu \mathrm{L}$ of Nafion ${ }^{\circledR}$ (5wt\%, Sigma-Aldrich), for a Nafion-to-catalyst mass ratio 126 of $0.175: 1$, and $400 \mu \mathrm{L}$ of a mixture of isopropanol (IPA) and ultrapure water (IPA: $\mathrm{H}_{2} \mathrm{O}, 3: 2$ ). The supporting 127 electrolyte was a $0.1 \mathrm{M} \mathrm{NaOH}$ aqueous solution. $\mathrm{N}_{2}$ (99.99\% Air Liquide) was employed to deoxygenate all 128 solutions. $\mathrm{O}_{2}$ (99.995\% Air Liquide) was employed to obtain a saturated solution for the oxygen reduction 129 reaction studies. Before electrocatalytic studies, all composites were submitted to activation process based 130 on 50 cyclic voltammograms (CVs) between 0.05 and $1.2 \mathrm{~V}$ vs RHE at a scan rate of $0.1 \mathrm{~V} \mathrm{~s}^{-1}$ in deaerated 131 supporting electrolyte. After that, a blank voltammetry between the same potential limits in $\mathrm{N}_{2}$ at $0.02 \mathrm{Vs}^{-1}$ 132 was recorded.

133 To determine the electrocatalytic activity of the catalysts two main reactions were studied: the ORR and the 134 OER. The ORR activity was tested with a polarization curve between 1.0 and $0.05 \mathrm{~V}$ vs. RHE (negative going 
scan) obtained at a scan rate of $0.005 \mathrm{~V} \cdot \mathrm{s}^{-1}$ while continuously flowing $\mathrm{O}_{2}$. Prior to ORR polarization curves,

136 all the composites were maintained at $1.0 \mathrm{~V}$ for $60 \mathrm{~s}$. This study was performed at different electrode 137 rotation speeds (rpm) to calculate the number of electrons using Koutecký-Levich plots. The measurement 138 was performed keeping the ring at $1.2 \mathrm{~V}$ vs. RHE in order to detect $\mathrm{H}_{2} \mathrm{O}_{2}$ formation. For the OER 139 measurement, a polarization curve between 0.7 and $1.8 \mathrm{~V}$ vs. RHE (positive going scan) was recorded at $1400.005 \mathrm{~V} \cdot \mathrm{s}^{-1}$ and $1600 \mathrm{rpm}$. In this case, the ring was kept at $0.4 \mathrm{~V}$ vs. RHE (for quantification of the evolved $\mathrm{O}_{2}$ 141 by ORR) [7].

142 In order to investigate the stability of the catalysts, two essays were performed considering both ORR and 143 OER reactions. For the ORR, 6500 cycles were performed by triangular potential cycling between 0.4 and 0.9 $144 \mathrm{~V}$ vs. RHE at a scan rate of $0.2 \mathrm{Vs}^{-1}$. After that, the ORR polarization curve was performed to compare this 145 signal with initial results. For the OER, the stability was assessed by a chronopotentiometric procedure 146 consisting of on/off rectangular cycles, maintaining $5 \mathrm{~mA} \mathrm{~cm}{ }^{-2}$ of current density for $180 \mathrm{~s}$ followed by a 147 period of $90 \mathrm{~s}$ at zero current, with a cut-off potential of $1.9 \mathrm{~V}$ vs. RHE [39-41].

\section{Results and discussion}

\subsection{Physicochemical characterization of $\mathrm{Ti} / \mathrm{NrGO}$ and $\mathrm{Co} / \mathrm{NrGO}$ composites}

151 Elemental analysis and ICP-OES values of $\mathrm{Co} / \mathrm{NrGO}$ and $\mathrm{Ti} / \mathrm{NrGO}$ are given in Table 1 . Chemical analysis shows similar amount of metal loading and metal to carbon atomic ratio. However, elemental analysis reveals higher nitrogen content in the bulk material for the cobalt-based composite, from $2 \mathrm{wt} \%$ in Ti/NrGO to $9 \mathrm{wt} \%$ in $\mathrm{Co} / \mathrm{NrGO}$. Considering that the same procedure was used for both composites, it appears that cobalt aids in fixating nitrogen to the composite in a larger extent than titanium.

Table 1 Metal loading (from ICP-OES) and elemental analysis ( $\mathrm{Me}=\mathrm{Ti}$ or $\mathrm{Co}$ )

\begin{tabular}{|l|l|c|c|c|}
\hline Sample & $\begin{array}{l}\text { Metal } \\
\text { loading } \\
\text { (wt\%) }\end{array}$ & $\mathbf{C}(\mathbf{w t} \%)$ & $\mathbf{N}(\mathbf{w t} \%)$ & atomic ratio \\
\hline Ti/NrGO & 22 & 54 & 2 & 0.1 \\
\hline Co/NrGO & 25 & 59 & 9 & 0.09 \\
\hline
\end{tabular}

158 The morphology of the composites was investigated by SEM. Figure 1 displays SEM images of Ti/NrGO (A) 159 and $\mathrm{Co} / \mathrm{NrGO}$ (B). Both composites show metal nanoparticles anchored on the $\mathrm{N}$-doped reduced graphene 160 oxide sheets. In general, the dispersion of the metal nanoparticles seems uniform in both catalysts with 161 some agglomerates of small particles observed at low magnification SEM captures. However, both 162 composites present great differences when observed by TEM. As shown in Figure 1C and E, TEM images of $\mathrm{Co} / \mathrm{NrGO}$ show metal nanoparticles with an average diameter of $60 \mathrm{~nm}$ (histogram inserted in Figure 1E), 
while the average particle size of the $\mathrm{Ti} / \mathrm{NrGO}$ corresponds to $7 \mathrm{~nm}$ (Figure $1 \mathrm{D}$ and $\mathrm{F}$, histogram inserted in

165

166

167

168

169

170

171

172

173

174

175

176

177

178 Figure 1F).

The structures of the composites and graphene oxide (GO) were investigated by means of XRD (Figure 2A). GO exhibits an intense peak at $2 \theta=10.8^{\circ}$ corresponding to the increased interlayer spacing of graphite due to the intercalation of oxygen-containing functional groups and water between the graphitic layers [42]. However, during the synthesis process of the $\mathrm{Ti} / \mathrm{NrGO}$ and $\mathrm{Co} / \mathrm{NrGO}$ composites, the diffraction peak of graphene oxide at $10.8^{\circ}$ is considerably shifted to a higher $2 \theta$ angle of $26.6^{\circ}$, which can be attributed to disordered layers of graphitic carbon from graphene (JCPDS 13-0148) [43]. That means that the GO is converted to reduced graphene oxide ( $\mathrm{rGO}$ ), and at the same time, urea is carbonized to obtain nitrogen doped carbon ( $\mathrm{NrGO}$ ). $\mathrm{Co} / \mathrm{NrGO}$ composite shows diffraction peaks at $2 \theta$ angles of $44.3^{\circ}, 51.6^{\circ}$ and $75.9^{\circ}$ corresponding to cobalt with face-centered cubic structure (JCPDS 15-0806). These peaks correspond to the (111), (200) and (220) crystalline lattice facets, respectively, of metallic cobalt indicating that metallic Co is the dominant form of the crystalline component [31]. The X-ray diffraction pattern of the Ti/NrGO composite (Figure 2A) exhibits the diffraction peaks attributable to $\mathrm{TiO}_{2}$-Anatase (JCPDS 89-4921) and $\mathrm{TiO}_{2}-$ Rutile phases (JCPDS 89-4202).
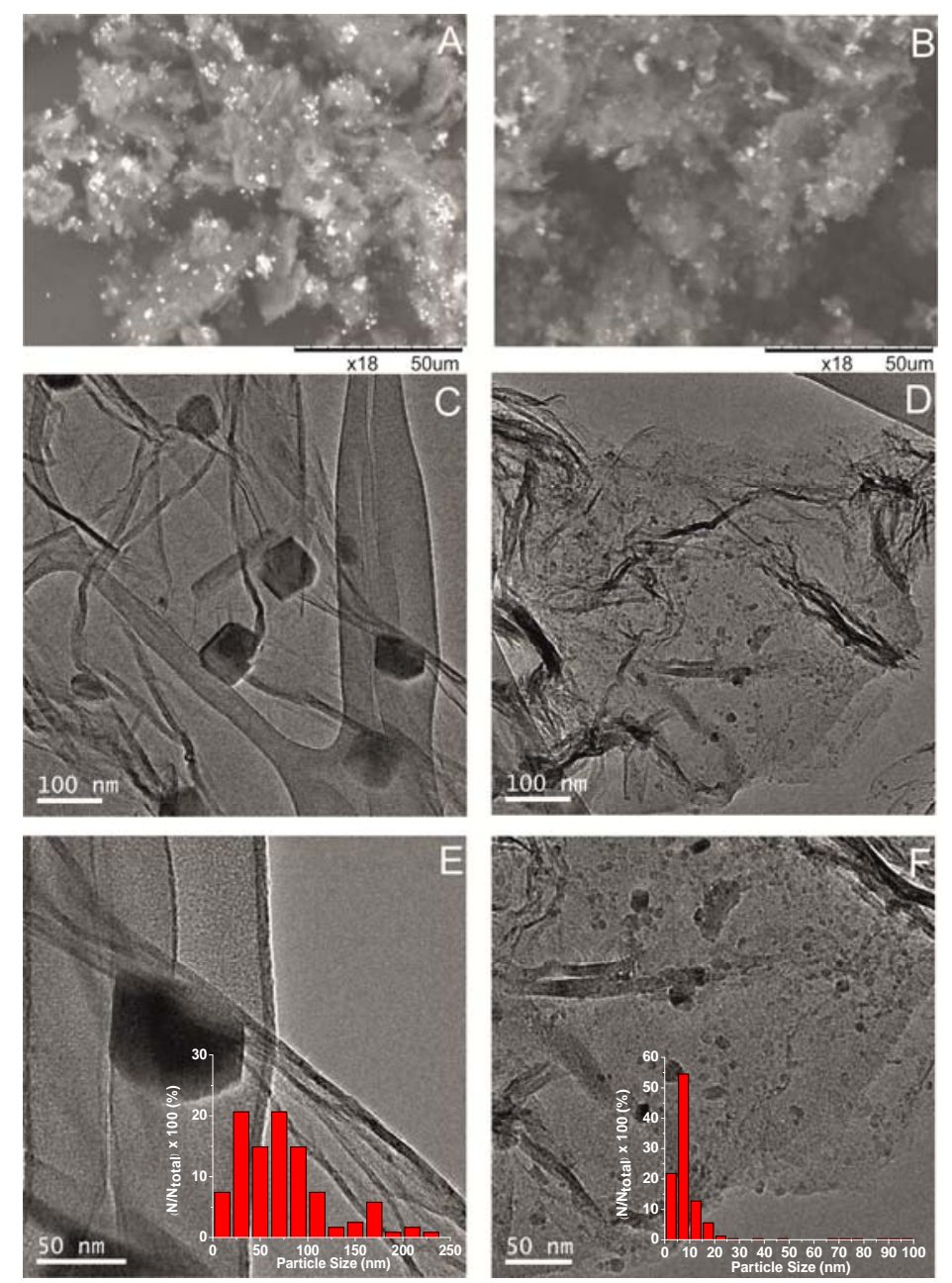

180 Figure 1. SEM images of $\mathrm{Co} / \mathrm{NrGO}(\mathrm{A})$ and $\mathrm{Ti} / \mathrm{NrGO}$ (B). TEM images of $\mathrm{Co} / \mathrm{NrGO}$ (C and E) and Ti/NrGO (D and F). The 
183 The structural and morphological features of the composites were further investigated using Raman spectroscopy. The corresponding spectra of $\mathrm{Co} / \mathrm{NrGO}, \mathrm{Ti} / \mathrm{rGO}$ and graphene oxide are displayed in Figure $2 \mathrm{~B}$.

185 Both composites show two well-defined bands corresponding to the $D$ and $G$ bands of graphene which 186 appear at around $1580 \mathrm{~cm}^{-1}$ and $1350 \mathrm{~cm}^{-1}$, respectively. As is known, the $\mathrm{G}$ band related to the E2g vibration mode of $\mathrm{sp}^{2}$ carbon domains can be used to explain the degree of graphitization, while the $\mathrm{D}$ band is associated with structural defects and partially disordered structures of the $\mathrm{sp}^{2}$ domains [44]. The extent of defects in the composites is quantified by estimating the relative intensities of these two bands $\left(I_{D} / I_{G}\right.$ ratio). For $\mathrm{Co} / \mathrm{NrGO}$ and $\mathrm{Ti} / \mathrm{NrGO}$ composites, the $\mathrm{I}_{\mathrm{D}} / \mathrm{I}_{\mathrm{G}}$ values are 0.98 and 1.00 , respectively, being slightly larger than graphene oxide $\left(\mathrm{I}_{\mathrm{D}} / \mathrm{I}_{\mathrm{G}}=0.89\right)$. This indicates that the density of defects of the resultant $\mathrm{NrGO}$ phase is similar between both composites and slightly larger for the graphene oxide used as precursor. It appears that the synthesis of composites introduced more surface defects, which could positively contribute to the electroactivity [45]. Furthermore, Raman bands at $476 \mathrm{~cm}^{-1}$ and $681 \mathrm{~cm}^{-1}$ in Co/NrGO composite can be assigned to $\mathrm{F}_{2 \mathrm{~g}}^{1}$ and $\mathrm{A}_{1 \mathrm{~g}}$ modes, respectively, of $\mathrm{CO}_{3} \mathrm{O}_{4}$ nanoparticles [46-48]. The presence of anatase and rutile phases of titania are also confirmed in the Raman spectrum of Ti/NrGO composite (Figure 2B). Weak Raman bands at 143, 199, 395 and $632 \mathrm{~cm}^{-1}$ are attributed to anatase phase of titania, while the presence of
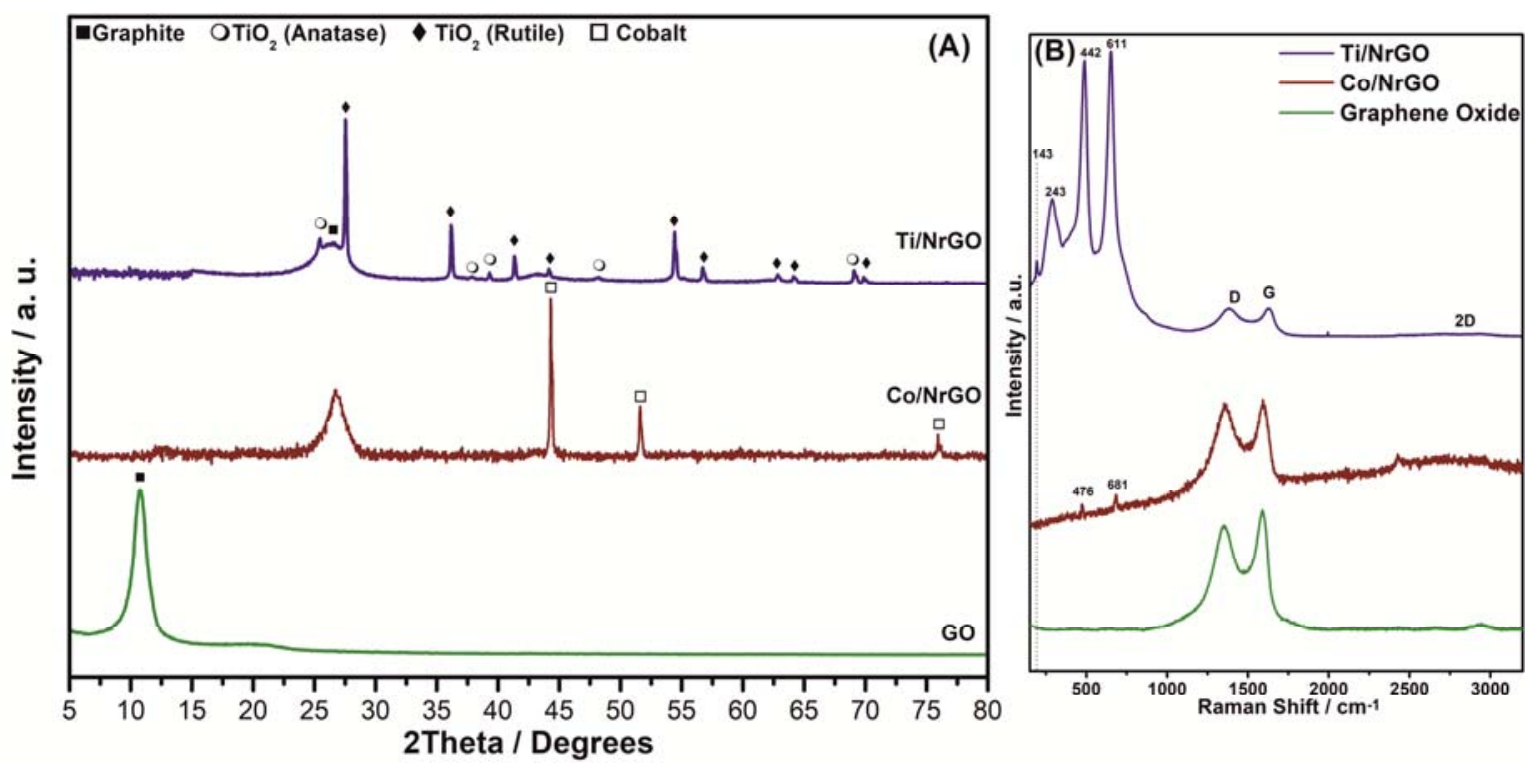

Figure 2. (A) XRD patterns of $\mathrm{GO}, \mathrm{Ti} / \mathrm{NrGO}$ and $\mathrm{Co} / \mathrm{NrGO}$; (B) Raman spectra of $\mathrm{Co} / \mathrm{NrGO}, \mathrm{Ti} / \mathrm{NrGO}$ and graphene oxide

The nature of the surface species of the composites was investigated by XPS analysis (Figure 3). The highresolution XPS spectrum of the $\mathrm{N}$ 1s peak of Ti/NrGO (Figure 3A) and $\mathrm{Co} / \mathrm{NrGO}$ (Figure 3B) composites reveals four components with the binding energies centered at about 398.1, 399.3, 400.7 and $402 \mathrm{eV}$, corresponding to pyridinic $\mathrm{N}$, pyrrolic $\mathrm{N}$, quaternary $\mathrm{N}$ and oxidized $\mathrm{N}$, respectively. Moreover, $\mathrm{Ti} / \mathrm{NrGO}$ shows an additional component centered at $396.5 \mathrm{eV}$ assigned to $\mathrm{N}-\mathrm{Ti}$ interaction. 
Figure $3 \mathrm{C}$ displays the Ti $2 \mathrm{p}$ XPS spectrum of Ti/NrGO composite. This spectrum shows a structure of two overlapping doublets. The $\mathrm{Ti} 2 \mathrm{p}_{3 / 2}$ peak centered at $459.1 \mathrm{eV}$ is attributed to $\mathrm{Ti}^{4+}$ state [51]. Upon comparison with a pristine $\mathrm{TiO}_{2}$ sample $[52,53]$, it is observed that the signal is slightly shifted from the corresponding $458.5 \mathrm{eV}$ peak to higher energy region. The shift of binding energy towards the higher energy

212 region can be attributed to the transfer of electron density from $\mathrm{Ti}$ to $\mathrm{NrGO}$ in the prepared $\mathrm{Ti} / \mathrm{NrGO}$ 213 composite. Additionally, a shoulder peak at $456.9 \mathrm{eV}$ is assigned to $\mathrm{Ti}^{3+}$ defects $[51,54] . \mathrm{Ti}^{3+}$ species on the 214 surface or in bulk $\mathrm{TiO}_{2}$ are known to be unstable and easily oxidized upon calcination. However, these species are believed to be stabilized upon hybridization with $\mathrm{N}$-doped reduced graphene oxide in our composite.

217 Figure 3D shows the Co $2 p$ XPS spectrum of the Co/NrGO composite, which shows a complex structure of 218 four overlapping doublets that can be ascribed to different contributions. The deconvolution of Co $2 p$ profiles includes two pairs of spin-orbit doublet $2 \mathrm{p}_{3 / 2}$ and $2 \mathrm{p}_{1 / 2}$ implying the coexistence of $\mathrm{Co}^{2+}$ and $\mathrm{Co}^{3+}$ [17]. The first doublet of Co $2 p_{3 / 2}$ and Co $2 p_{1 / 2}$ at $781.1 \mathrm{eV}$ and $796.1 \mathrm{eV}$ respectively (separated by $15.03 \mathrm{eV}$ ) 221 is related to $\mathrm{Co}_{3} \mathrm{O}_{4}$ [55]. The second doublet at $784.6 \mathrm{eV}$ of $\mathrm{Co} 2 \mathrm{p}_{3 / 2}$ is associated to $\mathrm{Co}^{2+}$. The doublet centered at $787.5 \mathrm{eV}$ could indicate the existence of Co-N bond [56, 57], and the Co $2 p_{3 / 2}$ peak at $791.2 \mathrm{eV}$ is assigned to shake-up (satellite) type peak, which indicates the presence of spinel $\mathrm{Co}_{3} \mathrm{O}_{4}$ with $\mathrm{Co}^{2+}$ in a tetrahedral coordination and an octahedral coordinated $\mathrm{Co}^{3+}[58]$.

Table 2. Summary of XPS data of the electrocatalysts (relative percentages in parenthesis).

\begin{tabular}{|c|c|c|c|c|c|c|}
\hline \multirow[t]{2}{*}{ Catalyst } & \multirow{2}{*}{$\begin{array}{c}\text { BE (eV) } \\
\text { N1s }\end{array}$} & \multirow{2}{*}{$\begin{array}{l}\mathrm{BE}(\mathrm{eV}) \\
\mathrm{Co} 2 \mathrm{p}_{3 / 2}\end{array}$} & \multirow{2}{*}{$\begin{array}{l}\mathrm{BE}(\mathrm{eV}) \\
\mathrm{Ti} 2 \mathrm{p}_{3 / 2}\end{array}$} & \multirow[t]{2}{*}{$\begin{array}{l}\text { Surface metal } \\
\text { loading (\%wt) }\end{array}$} & \multicolumn{2}{|c|}{$\begin{array}{c}\text { Surface atomic } \\
\text { ratio }\end{array}$} \\
\hline & & & & & $\mathrm{Me} / \mathrm{N}$ & $\mathrm{Me} / \mathrm{C}$ \\
\hline Ti/NrGO & $\begin{array}{l}396.5(8) \\
398.1(30) \\
399.3(24) \\
400.7(22) \\
401.9(16)\end{array}$ & - & $\begin{array}{l}456.9(12) \\
459.1(88)\end{array}$ & 17 & 0.91 & 0.07 \\
\hline $\mathrm{Co} / \mathrm{NrGO}$ & $\begin{array}{l}398.2(35) \\
399.3(26) \\
400.8(27) \\
402.1(12)\end{array}$ & $\begin{array}{l}781.1(43) \\
784.5(29) \\
787.5(28)\end{array}$ & - & 24 & 0.96 & 0.09 \\
\hline
\end{tabular}

For better insight, the weight percentages of the elements are quantified using XPS and the corresponding values of atomic ratio $\mathrm{Me} / \mathrm{N}$ and $\mathrm{Me} / \mathrm{C}$ are presented in Table 2. The content of surface metal estimated from the XPS analysis is found to be $17 \mathrm{wt} \%$ for $\mathrm{Ti} / \mathrm{NrGO}$ and $24 \mathrm{wt} \%$ for $\mathrm{Co} / \mathrm{NrGO}$. Both composites present similar atomic ratio $\mathrm{Me} / \mathrm{N}$ and $\mathrm{Me} / \mathrm{C}$ close to 0.9 and 0.08 , respectively. The percentage of each type of 231 nitrogen, titanium, cobalt and carbon species has been estimated by evaluating the total area of the individual peaks in the deconvoluted $\mathrm{N} 1 \mathrm{~s}, \mathrm{Ti} 2 \mathrm{p}$, Co $2 \mathrm{p}$ and $\mathrm{C} 1 \mathrm{~s}$ respectively (Table 2). Comparing the Me/C 

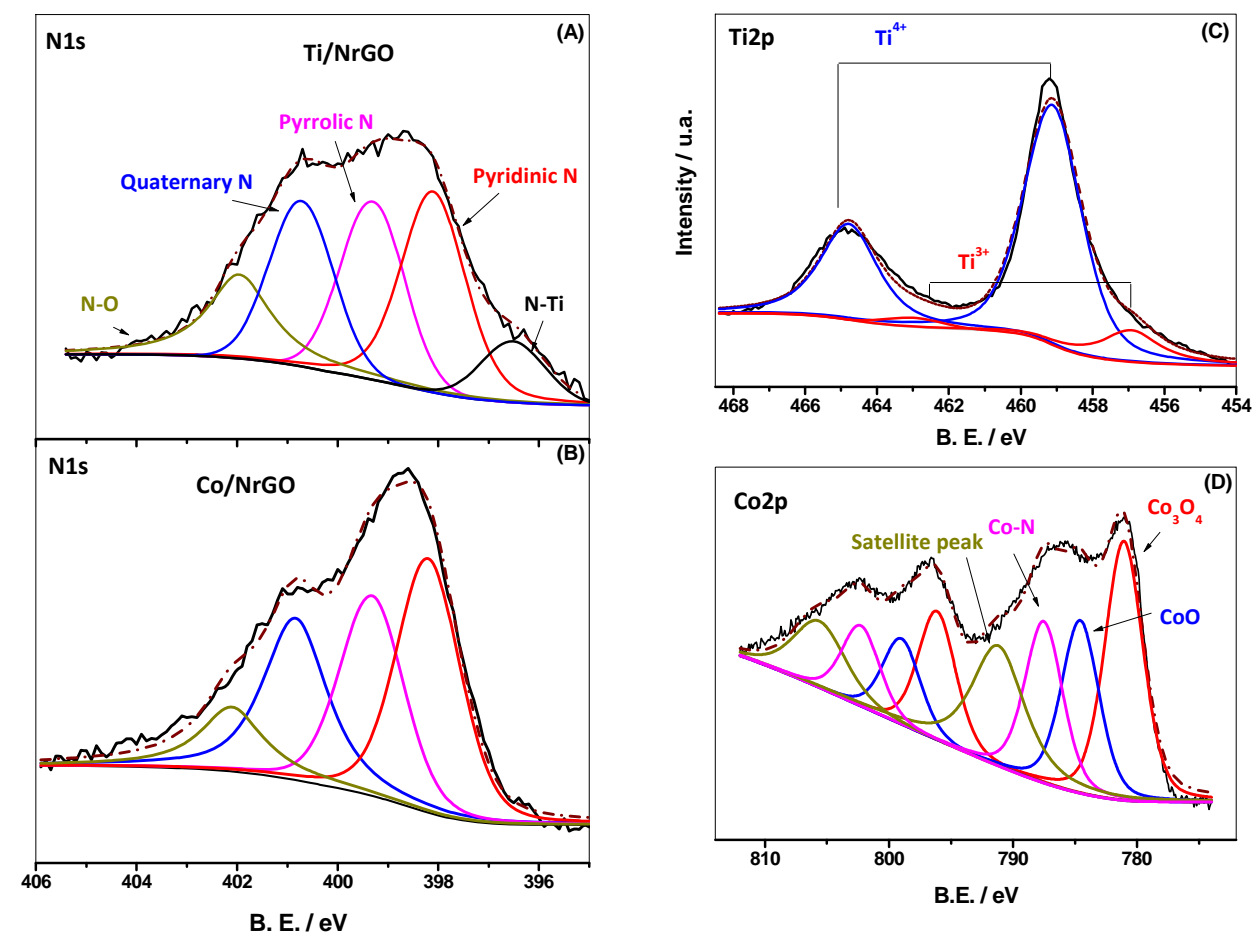

Figure 3. XPS high resolution spectra of: $\mathrm{N} 1 \mathrm{~s}$ of Ti/NrGO (A) and Co/NrGO (B) composites, Ti2p of Ti/NrGO composite (C) and $\mathrm{Co} 2 \mathrm{p}$ of $\mathrm{Co} / \mathrm{NrGO}$ composite (D).

3.2. Electrochemical characterization of composites towards oxygen reduction reaction (ORR)

The electrocatalytic activity of $\mathrm{Ti} / \mathrm{NrGO}$ and $\mathrm{Co} / \mathrm{NrGO}$ composites for the ORR was investigated by cyclic voltammetry in $0.1 \mathrm{M} \mathrm{NaOH}$ aqueous solution (deareated or saturated with $\mathrm{O}_{2}$ ) and idle mode (no rotation). As shown in Figure 4, the CVs of the composites obtained in deareated solution show a featureless voltammetric current, while their corresponding $\mathrm{CVs}$ obtained in $\mathrm{O}_{2}$-saturated solution exhibit cathodic peaks corresponding to the reduction of $\mathrm{O}_{2}$. This clearly indicates that both composites are electrochemically active for the ORR.

246 The cathodic sweep branch of $\mathrm{Ti} / \mathrm{NrGO}$ and $\mathrm{Co} / \mathrm{NrGO}$ composites recorded in $\mathrm{O}_{2}$-saturated alkaline medium 247 at a rotation rate of $1600 \mathrm{rpm}$ is shown in Figure 4C. A commercial Pt/C (20 wt\% Pt, Johnson \& Matthey) 248 catalyst was added for comparison. The voltammogram recorded in the deareated electrolyte was used to subtract the capacitive current contribution from the curve measured in presence of $\mathrm{O}_{2}$. As evidenced in Figure $4 \mathrm{C}, \mathrm{Pt} / \mathrm{C}$ shows the most positive onset potential, while the onset potential of the $\mathrm{Co} / \mathrm{NrGO}$ is 251 approximately $100 \mathrm{mV}$ more positive than the one obtained with the Ti/NrGO composite (Table 3).

252 Therefore, the ORR activity of the Co/NrGO is enhanced in comparison with the Ti/NrGO. It is well-known 
that nitrogen-doped carbon with transition metals such as Fe or Co presents a good catalytic activity for the ORR in alkaline electrolyte $[29,31,59]$. The enhanced electroactivity of the Co-based composite compared to the Ti-based one could be thus attributed to an improved kinetics for the catalytic sites derived from cobalt species [60]. Both in-house prepared NrGO-based catalysts present a lower net limiting diffusion current density (about $-4.5 \mathrm{~mA} \mathrm{~cm}{ }^{-2}$ ) compared to $\mathrm{Pt} / \mathrm{C}\left(-5.7 \mathrm{~mA} \mathrm{~cm}{ }^{-2}\right.$ ), which is directly ascribed to a lower number of transferred electrons, according to the Levich equation, and as will be demonstrated by using Koutecký-Levich plots.
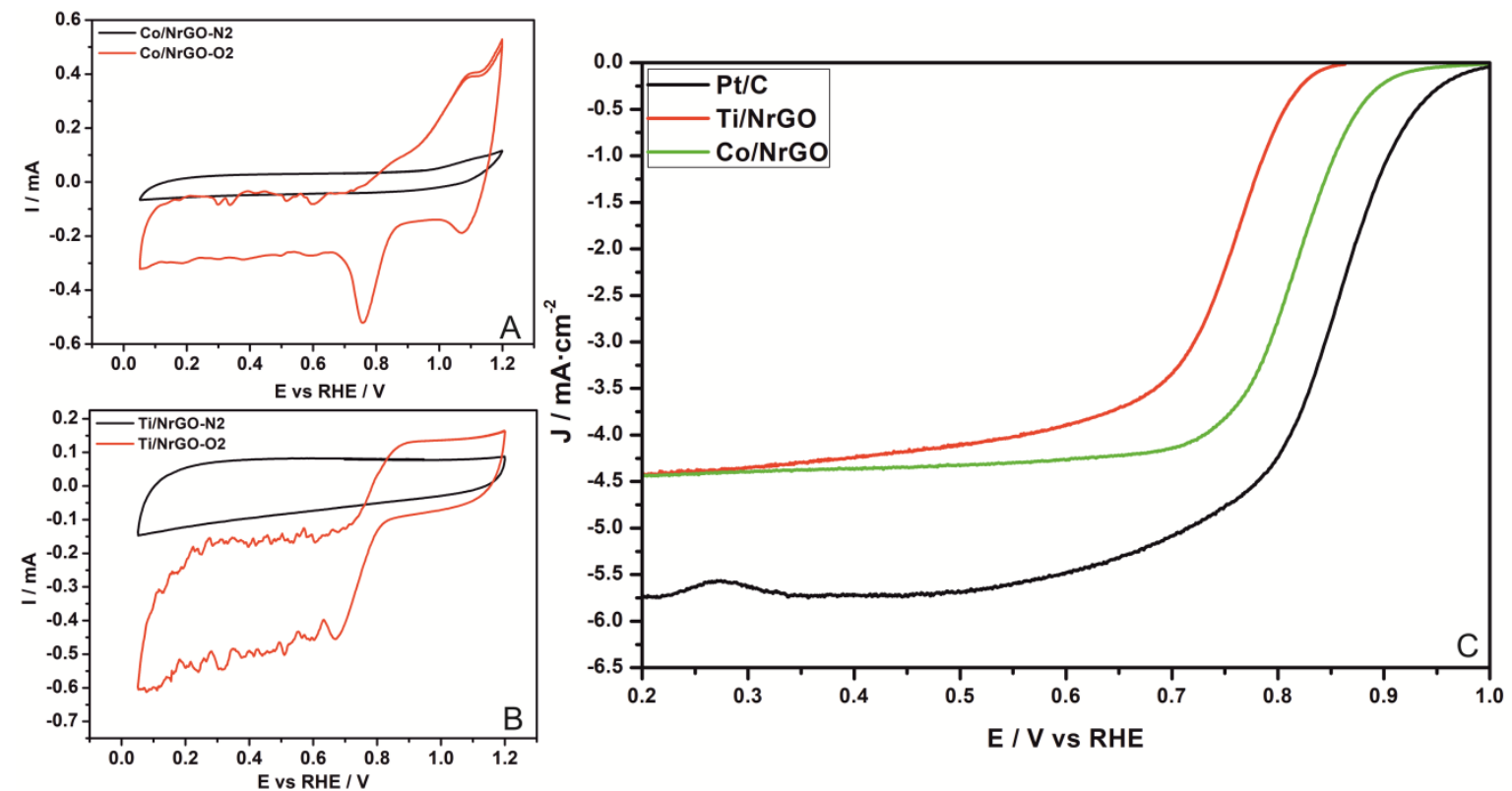

Figure 4. Cyclic voltammetries in $\mathrm{N}_{2}$ and $\mathrm{O}_{2}$ comparison of Ti/NrGO (A) and $\mathrm{Co} / \mathrm{NrGO}(\mathrm{B})$ in $0.1 \mathrm{M} \mathrm{NaOH}$ at a scan rate of $0.02 \mathrm{~V} \cdot \mathrm{s}^{-1}$. ORR linear voltammetry of $\mathrm{Co} / \mathrm{NrGO}, \mathrm{Ti} / \mathrm{NrGO}$ and commercial $\mathrm{Pt} / \mathrm{C}$ catalyst $(\mathrm{C})$ in $0.1 \mathrm{M} \mathrm{NaOH}$, at a scan rate

To gain insight into the electron-transfer kinetics involved in the ORR, polarization curves of the catalysts in $\mathrm{O}_{2}$-saturated $0.1 \mathrm{M} \mathrm{NaOH}$ solution were measured at various rotation rates. Figure $5 \mathrm{~A}$ and $\mathrm{B}$ display the voltammetric profiles of the polarization curves of $\mathrm{Co} / \mathrm{NrGO}$ and $\mathrm{Ti} / \mathrm{NrGO}$ composites, respectively. Both catalysts show an increased current intensity with increasing rotation rate due to the enhancement of the oxygen diffusion. For the study of the number of transferred electrons ( $n$ ), Koutecký-Levich (K-L) plots derived from the ORR polarization curves have been plotted in Figure $5 C$ and $D$ [61], following the K-L equation (Equation 1):

$$
\frac{1}{j}=\frac{1}{j_{k}}+\frac{1}{j_{d}}=\frac{1}{j_{k}}+\frac{1}{0.62 n F C_{O_{2}} D_{O_{2}}^{2 / 3} v^{-1 / 6} \omega^{1 / 2}}
$$


where $j$ is the experimental current density, $j_{k}$ is the kinetic current density, $j_{d}$ is the diffusion limited current density, $\omega$ is the electrode rotation rate $\left(\mathrm{rad} \mathrm{s}^{-1}\right), F$ is the Faraday constant $\left(96485 \mathrm{C} \mathrm{mol}^{-1}\right), \mathrm{D}_{02}$ is the diffusion coefficient of $\mathrm{O}_{2}$ in $0.1 \mathrm{M} \mathrm{NaOH}\left(1.9 \cdot 10^{-5} \mathrm{~cm}^{2} \mathrm{~s}^{-1}\right), \mathrm{C}_{02}$ is the solubility of $\mathrm{O}_{2}$ in $0.1 \mathrm{M} \mathrm{NaOH}\left(1.2 \cdot 10^{-6}\right.$ $\left.\mathrm{mol} \mathrm{cm} \mathrm{cm}^{-3}\right)$ and $v$ is the kinematic viscosity of $0.1 \mathrm{M} \mathrm{NaOH}\left(1.1 \cdot 10^{-2} \mathrm{~cm}^{2} \mathrm{~s}^{-1}\right)$ [62-64].
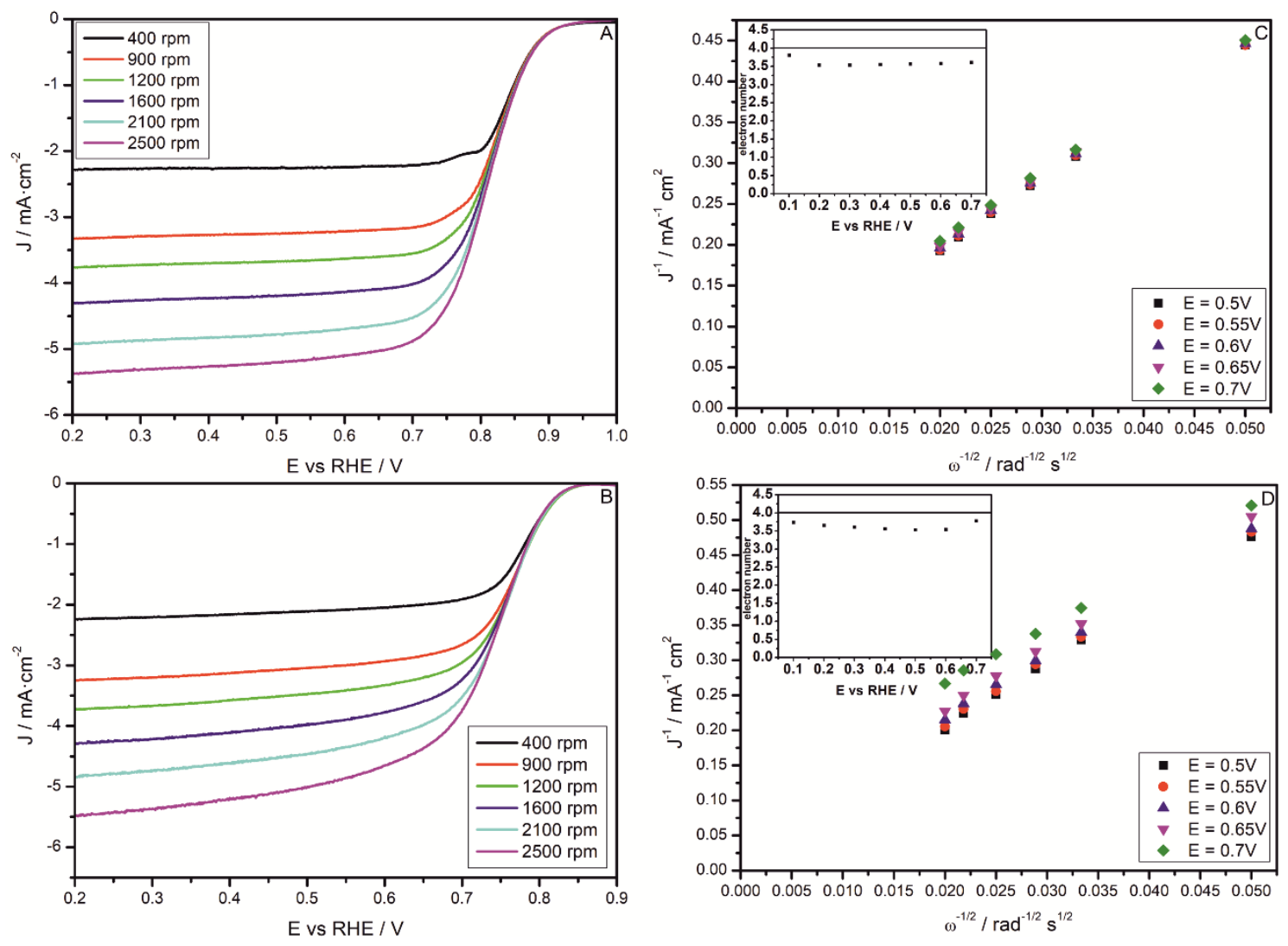

Figure 5 Linear sweep voltammetries in $\mathrm{O}_{2}$-saturated $0.1 \mathrm{M} \mathrm{NaOH}$ aqueous solution for $\mathrm{Co} / \mathrm{NrGO}(\mathrm{A})$ and $\mathrm{Ti} / \mathrm{NrGO}$ (B) composites, the legend indicates RDE rotation rate, scan rate $=0.005 \mathrm{~V} \cdot \mathrm{s}^{-1}$. Koutecký-Levich plots for Co/ $\mathrm{NrGO}$ (C) and $\mathrm{Ti} / \mathrm{NrGO}(\mathrm{D})$ composites at various electrode potentials.

The number of transferred electrons is similar for both composites, with values of 3.5 and 3.6 for the Ti-based and the Co-based composites, respectively. Moreover, $\mathrm{n}$ value barely changes with the applied potential, as observed in the inset graphs of Figures $5 \mathrm{C}$ and $5 \mathrm{D}$. It indicates a reduction mechanism close to complete reduction of oxygen to water $(n=4)$ but with a small contribution of sites (about $25 \%$ ) with partial reduction to hydrogen peroxide. As a consequence, the largest difference between the two composites was found in the potential at which oxygen reduction occurs rather than in the mechanism. Indeed, by comparing the half-wave potential reported in

Table $3\left(E_{1 / 2}\right)$, i.e. the potential in the mixed kinetic-diffusion controlled region, ORR takes place at an 293 overpotential about $60 \mathrm{mV}$ lower in the case of the cobalt-based composite. Nevertheless, the gap is still about $40 \mathrm{mV}$ when compared to a Pt/C catalyst as a reference for the ORR. 
Table 3 Electrokinetic parameters from ORR and OER electrochemical characterization

\begin{tabular}{|l|l|l|l|l|l|}
\hline Sample & \multirow{2}{*}{$\mathrm{E}_{\text {onset }}$ ORR (V) } & $\mathrm{E}_{1 / 2}(\mathrm{~V})$ & $\mathrm{n}$ (electron transfer) & $\begin{array}{l}\Delta \mathrm{E}_{1 / 2} \text { after } \\
6500 \text { cycles } \\
(\mathrm{mV})\end{array}$ & $\mathrm{E}_{\text {onset }}$ OER (V) \\
\hline $\mathrm{Ti} / \mathrm{NrGO}$ & 0.85 & 0.75 & 3.5 & 8 & 1.65 \\
\hline $\mathrm{Co} / \mathrm{NrGO}$ & 0.95 & 0.81 & 3.6 & 13 & 1.51 \\
\hline $\mathrm{Pt} / \mathrm{C}$ & 1.00 & 0.85 & 4.0 & 120 & na \\
\hline IrO 2 & $\mathrm{na}$ & $\mathrm{na}$ & $\mathrm{na}$ & $\mathrm{na}$ & 1.53 \\
\hline
\end{tabular}

na $=$ not applicable

299 3.3. Electrochemical characterization of composites towards oxygen evolution reaction (OER)

300 The activity of composites and $\mathrm{IrO}_{2}$ commercial sample (Alfa Aesar, 99\% purity) toward OER by water 301 oxidation in alkaline medium was studied by the ring-disk technique. The bottom panel of Figure 6 shows 302 the anodic current delivered by the disk electrode during the anodic sweep potential, whereas the top panel 303 depicts the current delivered by the ring electrode that is fixed at $0.4 \mathrm{~V}$ vs. RHE. Thus, molecular oxygen 304 produced at the disk is further reduced at the ring and, consequently, the oxygen evolution reaction can be 305 discerned from side reactions.

306 An anodic faradaic current is observed at potentials higher than $1.5 \mathrm{~V}$ vs. RHE for all catalysts. The onset 307 potential for this anodic current increases in the following way: $\mathrm{Co} / \mathrm{NrGO}<\mathrm{IrO}_{2}<\mathrm{Ti} / \mathrm{NrGO}$. The rise of the 308 ring signal indicates that anodic currents developed at the disk electrode at higher potentials than $1.5 \mathrm{~V}$ are 309 related to the water oxidation reaction, i.e. oxygen evolution reaction. Moreover, the determination of the 310 onset potential is more accurate from the ring signal since side reactions, such as formation of metal oxides, 311 do not account to the ring current. The onset potential values for $\mathrm{Co} / \mathrm{NrGO}$ and $\mathrm{IrO}_{2}$ are $1.51 \mathrm{~V}$ and $1.53 \mathrm{~V}$, 312 respectively. It is noticeable the low activity of Ti/NrGO toward the OER in this potential range. Therefore, $313 \mathrm{Co} / \mathrm{NrGO}$ composite develops the highest catalytic activity toward the OER. 


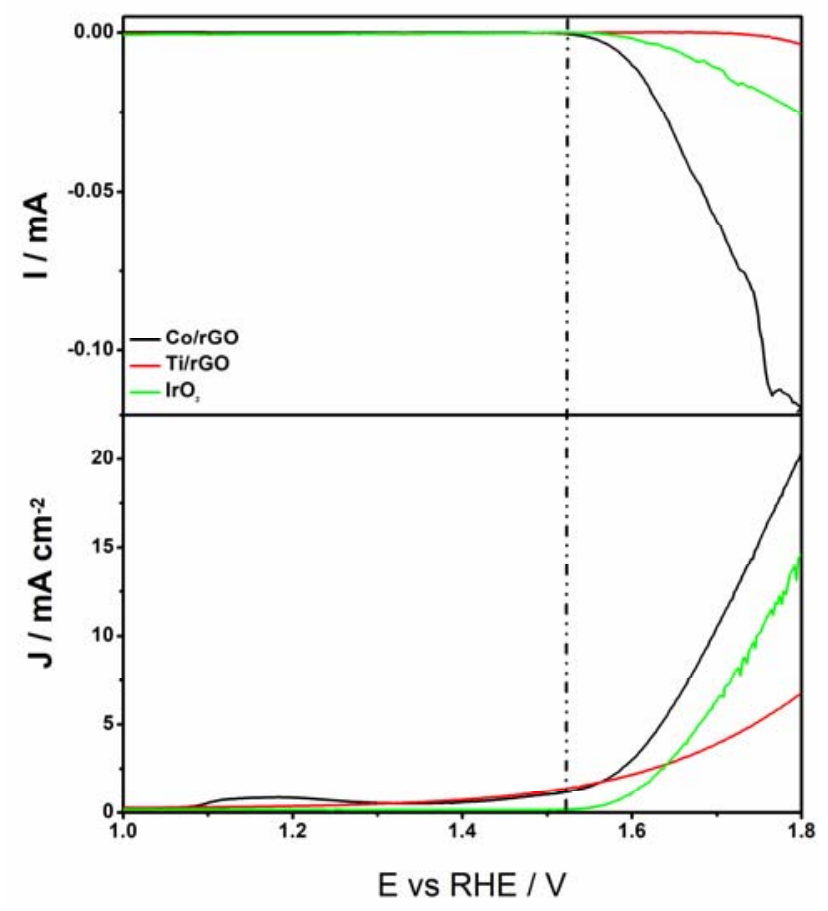

Figure $6 \mathrm{OER}$ activities of Ti/NrGO, $\mathrm{Co} / \mathrm{rGO}$ and $\mathrm{IrO}_{2}$ catalysts in $0.1 \mathrm{M} \mathrm{NaOH}$ at $1600 \mathrm{rpm}$. Low panel: Disk signal recorded at $5 \mathrm{mV} \cdot \mathrm{s}^{-1}$. Top panel: ring's current recorded at $0.4 \mathrm{~V}$ vs. RHE.

3.4. Composites electrochemical stability

To study the electrochemical stability of the catalysts, two different accelerated durability tests were performed. The first accelerated durability test was executed for the ORR by potential cycling between 0.4 and $0.9 \mathrm{~V}$ vs. RHE in $\mathrm{O}_{2}$-saturated $0.1 \mathrm{M} \mathrm{NaOH}$ electrolyte for 6500 cycles at a scan rate of $0.2 \mathrm{~V} \mathrm{~s}^{-1}$. The ORR linear sweep voltammetries before and after the potential cycling procedure are presented in the bottom panels of Figure $7(\mathrm{~A}-\mathrm{C})$. The half wave potential decay $\left(\Delta \mathrm{E}_{1 / 2}\right)$ for $\mathrm{Ti} / \mathrm{NrGO}$ and $\mathrm{Co} / \mathrm{NrGO}$ composites are found to be $8 \mathrm{mV}$ and $13 \mathrm{mV}$, respectively (Table 3). Thus, the degradation in the composites is much less prominent than in the $\mathrm{Pt} / \mathrm{C}$ catalyst $(120 \mathrm{mV})$. On the other hand, the limiting current density decreased after cycling for our catalysts. According to Levich equation, this decay could be ascribed to either a variation of the number of transferred electrons ( $n$ ) or to diffusion related phenomena, since the other parameters remained unchanged. The $\mathrm{H}_{2} \mathrm{O}_{2}$ formation yield, determined from the ring current directly associated to the formation of hydrogen peroxide, was observed to barely change after potential cycling, about $20 \%$ associated to $n=3.6$. The electrochemical response in the deaerated electrolyte was also determined by cyclic voltammetry before and after the 6500 potential cycles, as shown in Figure 7(D-E). A significant increase of double layer capacitance was noticed, indicating the formation of oxygen functionalities on the graphene surface. Hence, a larger extent of surface oxidation may cause a slight decrease of apparent diffusion coefficient through the porosity of carbon composite, thus affecting negatively the limiting current density after the stability test. In any case, these accelerated durability results clearly indicate that both composites have remarkable stability under the induced electrochemical environments at relatively high 

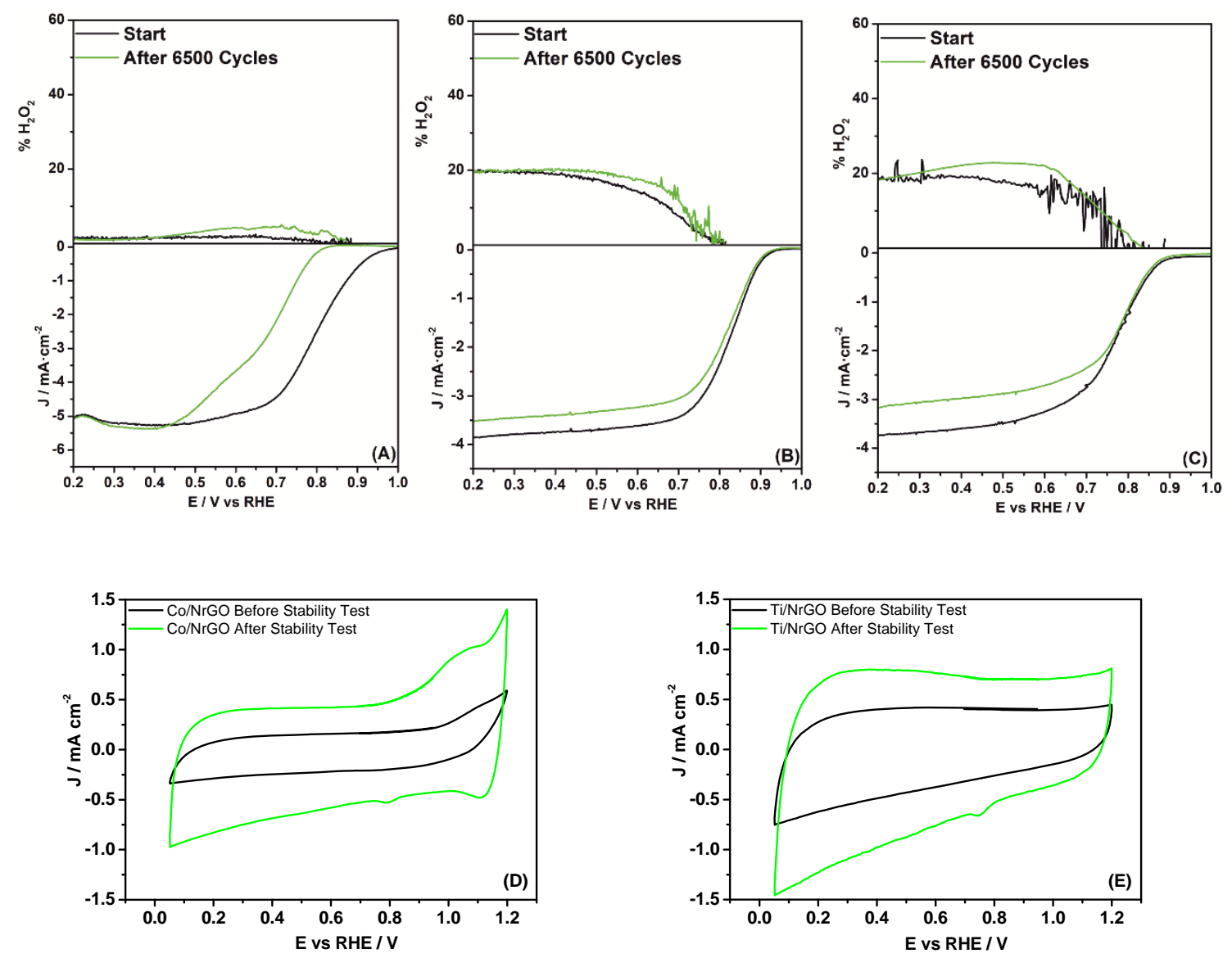

Figure 7. ORR activity by linear sweep voltammetry at $1600 \mathrm{rpm}$ (bottom) and $\mathrm{H}_{2} \mathrm{O}_{2}$ yield (top) by RRDE experiments in $\mathrm{O}_{2}$-saturated 0.1M NaOH electrolyte at the beginning and after 6500 potential cycles (0.4-0.9 V vs. RHE) for Pt/C (A), potential cycles for (D) Co/NrGO and (E) Ti/NrGO.

The second accelerated durability test consisted of chronopotentiometric measurement with rectangular cycles at $5 \mathrm{~mA} \cdot \mathrm{cm}^{-2}$ for $180 \mathrm{~s}$ followed by open circuit (zero current) during $30 \mathrm{~s}$, with a cut-off potential of $1.9 \mathrm{~V}$ vs. RHE. Figure 8 shows the stability cycles of Co/NrGO (Figure 8A) and Ti/NrGO (Figure 8B) in 0.1M $\mathrm{NaOH}$. This kind of fast and highly demanding test accelerates the degradation of the material at highly positive potentials [37]. As can be ascertained from Figure $8 \mathrm{~A}$, the $\mathrm{Co} / \mathrm{NrGO}$ sustains 18 cycles prior to reaching the cut-off potential ( $1.9 \mathrm{~V}$ vs. RHE) in the evolution region. Therefore, the stability of the composite is significantly improved by using cobalt in the composite. However, $\mathrm{Ti} / \mathrm{NrGO}$ reaches the cut-off in the first charge-discharge cycle, which means that Ti composite is not stable enough under comparable oxygen production rate. 

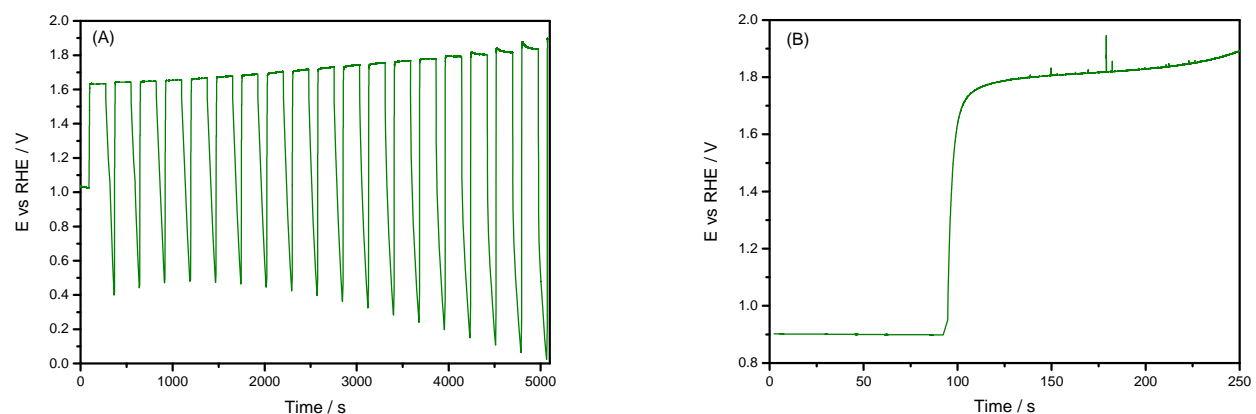

Figure 8 Chronopotentiometric rectangular cycles at $5 \mathrm{~mA} \mathrm{~cm}^{-2}$ for the $\mathrm{Co} / \mathrm{NrGO}(\mathrm{A})$ and $\mathrm{Ti} / \mathrm{NrGO}(\mathrm{B})$ in $0.1 \mathrm{M} \mathrm{NaOH}$.

\subsection{Interpretation of results}

361 It is known that the nanostructures of highly graphitized carbon are greatly dependent on the employed transition metals and nitrogen-carbon precursors, which are directly correlated to their catalytic activity [1, 21]. Furthermore, the catalytic performance of the composites is related with the chemical nature of the surface catalytic sites, which essentially depends on the synthesis method. In this work, a simple one-pot method via gel formation has been used to synthesize composites of $\mathrm{Co}$ and Ti with $\mathrm{N}$-doped graphene using urea as nitrogen source. The carbon derived from the carbonization process of urea-graphene serves as a matrix for hosting active nitrogen and metal moieties.

For $\mathrm{N}$-doped graphene, although the origin of the kinetic activity of $\mathrm{N}$-doped carbon materials is still being explored, extensive experimental and theoretical investigations point to those of pyridinic and quaternary nitrogen which play a crucial role in ORR activity $[65,66]$. The differences in the electronegativity of quaternary $\mathrm{N}$ promote the exchange of electrons between $\mathrm{N}$ atoms and adjacent $\mathrm{C} \mathrm{p}_{z}$ orbitals, and then $\mathrm{O}_{2}$ dissociation on the adjacent $\mathrm{C}$ atoms is improved along with the formation of a strong chemical bond between $\mathrm{O}$ and $\mathrm{C}$ [67]. While pyridinic $\mathrm{N}$ can be beneficial for the onset potential, other $\mathrm{N}$ species such as pyrrolic or oxidized $\mathrm{N}$ contribute in a lesser extent to the ORR activity of carbon materials. Recent research has shown that pyridinic $\mathrm{N}$ in $\mathrm{N}$-doped carbons creates the active sites for the ORR, accompanied by the formation of Lewis basic sites, on which the oxygen molecule is adsorbed on carbon atoms adjacent to the pyridinic $\mathrm{N}$ as the initial step of ORR [68]. But for metal- $\mathrm{Nx} / \mathrm{C}$, the situation might differ, the nature of the active sites remains under investigation [66]. In our composites, the percentage of pyridinic $\mathrm{N}$ and quaternary $\mathrm{N}$ depend on the transition metal used. According to Table 2 the total amount of pyridinic $\mathrm{N}$ and quaternary $\mathrm{N}$ is $52 \%$ in $\mathrm{Ti} / \mathrm{NrGO}$ and $62 \%$ in $\mathrm{Co} / \mathrm{NrGO}$, which seems to be important for improving the ORR activity of the $\mathrm{Co} / \mathrm{NrGO}$ composite. But also, a possible Co-N interaction should not be discarded. Liang et al.

382 reported a hybrid material containing $\mathrm{Co}_{3} \mathrm{O}_{4}$ nanocrystals grown on reduced graphene oxide, which 383 exhibited excellent performance towards the ORR. They proposed that $\mathrm{N}$ groups could induce nucleation and anchor sites for $\mathrm{Co}_{3} \mathrm{O}_{4}$ nanocrystals [69]. 
Although the activity of the $\mathrm{Ti} / \mathrm{NrGO}$ is not as good as that of Co/NrGO composite, it is important to note that we have obtained an active titanium-based composite in the ORR in alkaline environment, free of noble metal. The ORR onset potential for the Ti-based composite is $0.85 \mathrm{~V}$ (vs. RHE) and the number of electrons transferred is 3.5, showing superior stability than Pt/C after accelerated potential cycling in alkaline solution. Recently, Boppella et al. reported the synthesis of active and stable hybrid material $\mathrm{TiO}_{2} / \mathrm{rGO}$ hollow nanospheres for oxygen reduction reaction applications [51]. The results were attributed to a cooperative effect of the hybridation of $\mathrm{TiO}_{2}$ with $\mathrm{rGO}, \mathrm{Ti}^{3+}$ self-doping and the formation of a carbon-coating layer over the $\mathrm{TiO}_{2}$ particles. Though the structure of our titanium-based composite differs from the previous one, $\mathrm{TiO}_{2} / \mathrm{rGO}$ hollow nanospheres, we also observed the presence of $\mathrm{Ti}^{3+}$ species by XPS. The greatest novelty of our Ti/NrGO composite lies in the doping of graphene with nitrogen, which can facilitate interaction with $\mathrm{Ti}^{3+}$, as observed by XPS, and play an important role in providing an enhanced number of active sites for oxygen reduction reaction.

397 Due to the pyrolysis of precursor metals, a wide variety of structures are formed, and understanding which component of the composite is responsible for ORR and OER activities is tangled. According to XRD, chemical analysis and XPS results, the incorporation of $\mathrm{Ti}$ leads to a composite with both $\mathrm{TiO}_{2}$ anatase and rutile crystalline phases and $\mathrm{Ti}^{3+}$ species stabilized upon hybridization with $\mathrm{N}$-doped reduced graphene oxide. The ORR onset potential for the Ti-based composite is $0.85 \mathrm{~V}$ (vs. RHE) and the number of electrons transferred is 3.5, showing superior stability than Pt/C after accelerated potential cycling in alkaline solution. However, this composite shows low activity and stability for the OER. On the other hand, the composite consisting of metallic $\mathrm{Co}$ and $\mathrm{CO}_{3} \mathrm{O}_{4}$ nanocrystals grown on $\mathrm{N}$-doped reduced graphene oxide exhibits the best performance as bifunctional catalyst, with ORR and OER onset potentials of $0.95 \mathrm{~V}$ and $1.51 \mathrm{~V}$ (vs. RHE), respectively, and a number of electrons transferred of 3.6. The results reveal the presence of important structural features such us metallic $\mathrm{Co}$ as the predominant crystalline component, amorphous $\mathrm{Co}_{3} \mathrm{O}_{4} \mathrm{phase}$ and a possible coordination of Co-N-doped graphene. All of them seem to be fundamental for the high activity and stability to ORR and OER.

410 In summary, in good agreement with electrochemical measurements, the addition of Co metals to N-doped 411 graphene composite have demonstrated to be active for ORR and OER in alkaline environment. The synergy 412 effects of nitrogen doped graphene and $\mathrm{Co} / \mathrm{Co}_{2} \mathrm{O}_{3}$ benefit the active site formation and facilitate the high 413 performance for oxygen reduction and evolution reactions. Therefore, Co/NrGO composite offers an excellent combination of high activity and long-term performance durability.

\section{Conclusions}

Cobalt and Titanium $\mathrm{N}$-doped graphene composites have been synthesized by a one-step procedure 418 through the reaction of graphene oxide, urea and metal precursor. The introduction of metal to the carbon419 nitrogen matrix with graphene as carbon backbone induces changes in the surface chemistry with the 420 creation of metal-nitrogen bonds, as deduced by XPS analysis. The synergy effects of nitrogen-doped 421 graphene and $\mathrm{Co} / \mathrm{Co}_{2} \mathrm{O}_{3}$ benefit the active site formation and facilitate the high performance for oxygen 
reduction and evolution reactions. The addition of $\mathrm{Ti}$ and $\mathrm{Co}$ metals to $\mathrm{N}$-doped graphene composites creates active sites for the ORR in alkaline environment. Furthermore, Co/NrGO exhibits higher activity as bifunctional catalyst for both ORR and OER than Ti/NrGO, but the latter exhibited slightly larger stability after potential cycling in ORR.

\section{Acknowledgments}

Authors acknowledge financial support given by Spanish Ministry of Economy and Competitiveness (MINECO) through projects ENE2014-52158-C2-1-R and 2-R (co-founded by FEDER). J. M. Luque and G. Lemes also thank MINECO and Aragon Government, respectively, for their Ph.D. grants.

\section{References}

[1] G. Wu, A. Santandreu, W. Kellogg, S. Gupta, O. Ogoke, H. Zhang, H.-L. Wang, L. Dai, Carbon nanocomposite catalysts for oxygen reduction and evolution reactions: From nitrogen doping to transitionmetal addition, Nano Energy 29 (2016) 83-110.

[2] B. Paul, J. Andrews, PEM unitised reversible/regenerative hydrogen fuel cell systems: State of the art and technical challenges, Renewable and Sustainable Energy Reviews 79(Supplement C) (2017) 585-599.

[3] Y. Wang, D.Y.C. Leung, J. Xuan, H. Wang, A review on unitized regenerative fuel cell technologies, part-A: Unitized regenerative proton exchange membrane fuel cells, Renewable and Sustainable Energy Reviews 65 (2016) 961-977.

[4] N.-T. Suen, S.-F. Hung, Q. Quan, N. Zhang, Y.-J. Xu, H.M. Chen, Electrocatalysis for the oxygen evolution reaction: recent development and future perspectives, Chemical Society Reviews 46(2) (2017) 337-365.

[5] N. Danilovic, R. Subbaraman, K.C. Chang, S.H. Chang, Y. Kang, J. Snyder, A.P. Paulikas, D. Strmcnik, Y.T. for the Oxygen Evolution Reaction in Acidic Environments, Angewandte Chemie International Edition 53(51) (2014) 14016-14021.

[6] M. Shao, Q. Chang, J.-P. Dodelet, R. Chenitz, Recent Advances in Electrocatalysts for Oxygen Reduction Reaction, Chemical Reviews 116(6) (2016) 3594-3657.

[7] M. Roca-Ayats, G. García, J.L. Galante, M.A. Peña, M.V. Martínez-Huerta, Electrocatalytic stability of Ti based-supported Pt3Ir nanoparticles for unitized regenerative fuel cells, International Journal of Hydrogen Energy 39(10) (2014) 5477-5484.

452 [8] M. Roca-Ayats, E. Herreros, G. García, M.A. Peña, M.V. Martínez-Huerta, Promotion of oxygen reduction and water oxidation at Pt-based electrocatalysts by titanium carbonitride, Applied Catalysis B: Environmental $454183(2016) 53-60$.

455 [9] L. An, T.S. Zhao, Y.S. Li, Carbon-neutral sustainable energy technology: Direct ethanol fuel cells, Renewable \& Sustainable Energy Reviews 50 (2015) 1462-1468.

457 [10] A. Indra, P.W. Menezes, C. Das, Schmei, M. Driess, Alkaline electrochemical water oxidation with multishelled cobalt manganese oxide hollow spheres, Chemical Communications 53(62) (2017) 8641-8644.

459 [11] Z. Shan, P.S. Archana, G. Shen, A. Gupta, M.G. Bakker, S. Pan, NanoCOT: Low-Cost Nanostructured 460 Electrode Containing Carbon, Oxygen, and Titanium for Efficient Oxygen Evolution Reaction, Journal of the 461 American Chemical Society 137(37) (2015) 11996-12005. 
[12] H.W. Zhang, D.Z. Chen, Y. Xianze, S.B. Yin, Anion-Exchange Membranes for Fuel Cells: Synthesis Strategies, Properties and Perspectives, Fuel Cells 15(6) (2015) 761-780.

[13] M.V. Martínez-Huerta, M.J. Lázaro, Electrocatalysts for low temperature fuel cells, Catalysis Today 285 (2017) 3-12.

[14] J.W. Desmond Ng, Y. Gorlin, T. Hatsukade, T.F. Jaramillo, A Precious-Metal-Free Regenerative Fuel Cell for Storing Renewable Electricity, Advanced Energy Materials 3(12) (2013) 1545-1550. [15] J.W.D. Ng, M. Tang, T.F. Jaramillo, A carbon-free, precious-metal-free, high-performance O2 electrode for regenerative fuel cells and metal-air batteries, Energy \& Environmental Science 7(6) (2014) 2017-2024. [16] C. Tang, Q. Zhang, Can metal-nitrogen-carbon catalysts satisfy oxygen electrochemistry?, Journal of Materials Chemistry A 4(14) (2016) 4998-5001. [17] Q. Wang, W. Hu, Y. Huang, Nitrogen doped graphene anchored cobalt oxides efficiently bi-functionally catalyze both oxygen reduction reaction and oxygen revolution reaction, International Journal of Hydrogen Energy 42(9) (2017) 5899-5907.

[18] X. Zhong, Y. Jiang, X. Chen, L. Wang, G. Zhuang, X. Li, J.-g. Wang, Integrating cobalt phosphide and cobalt nitride-embedded nitrogen-rich nanocarbons: high-performance bifunctional electrocatalysts for oxygen reduction and evolution, Journal of Materials Chemistry A 4(27) (2016) 10575-10584. porous $\mathrm{N}$-doped carbon microtube sponge electrocatalyst for oxygen reduction and oxygen evolution reactions, Energy \& Environmental Science 9(10) (2016) 3079-3084.

[20] G. Wu, P. Zelenay, Nanostructured Nonprecious Metal Catalysts for Oxygen Reduction Reaction, Accounts of Chemical Research 46(8) (2013) 1878-1889.

[21] Q. Li, R. Cao, J. Cho, G. Wu, Nanocarbon Electrocatalysts for Oxygen Reduction in Alkaline Media for Advanced Energy Conversion and Storage, Advanced energy materials 4(6) (2014).

[22] L. Osmieri, R. Escudero-Cid, A.H.A. Monteverde Videla, P. Ocón, S. Specchia, Application of a non-noble Fe-N-C catalyst for oxygen reduction reaction in an alkaline direct ethanol fuel cell, Renewable Energy (2017). [23] L. Osmieri, A.H.A. Monteverde Videla, S. Specchia, Activity of Co-N multi walled carbon nanotubes electrocatalysts for oxygen reduction reaction in acid conditions, Journal of Power Sources 278 (2015) 296-307. [24] M. Ferrandon, A.J. Kropf, D.J. Myers, K. Artyushkova, U. Kramm, P. Bogdanoff, G. Wu, C.M. Johnston, P. Zelenay, Multitechnique Characterization of a Polyaniline-Iron-Carbon Oxygen Reduction Catalyst, The Journal of Physical Chemistry C 116(30) (2012) 16001-16013.

[25] L. Osmieri, A.H.A. Monteverde Videla, S. Specchia, Optimization of a Fe-N-C electrocatalyst supported on mesoporous carbon functionalized with polypyrrole for oxygen reduction reaction under both alkaline and acidic conditions, International Journal of Hydrogen Energy 41(43) (2016) 19610-19628.

[26] B.Y. Xia, Y. Yan, N. Li, H.B. Wu, X.W. Lou, X. Wang, A metal-organic framework-derived bifunctional oxygen electrocatalyst, 1 (2016) 15006.

497 [27] J. Du, F. Cheng, S. Wang, T. Zhang, J. Chen, M(Salen)-derived Nitrogen-doped M/C (M = Fe, Co, Ni) Porous Nanocomposites for Electrocatalytic Oxygen Reduction, Sci. Rep. 4 (2014).

[28] M.H. Seo, D. Higgins, G. Jiang, S.M. Choi, B. Han, Z. Chen, Theoretical insight into highly durable iron phthalocyanine derived non-precious catalysts for oxygen reduction reactions, Journal of Materials Chemistry

501 A 2(46) (2014) 19707-19716.

[29] B. Aghabarari, N. Nezafati, M. Roca-Ayats, M.C. Capel-Sánchez, M.J. Lázaro, M.V. Martínez-Huerta, Effect 503 of molybdophosphoric acid in iron and cobalt graphene/chitosan composites for oxygen reduction reaction, International Journal of Hydrogen Energy (2017). 

doped carbon as an efficient bifunctional electrocatalyst for oxygen reduction and evolution reactions, Nanoscale 6(24) (2014) 15080-15089.

508 [31] B. He, X. Chen, J. Lu, S. Yao, J. Wei, Q. Zhao, D. Jing, X. Huang, T. Wang, One-pot Synthesized Co/Co3O4-

509 N-Graphene Composite as Electrocatalyst for Oxygen Reduction Reaction and Oxygen Evolution Reaction,

510 Electroanalysis 28(10) (2016) 2435-2443.

511 [32] S. Mao, Z. Wen, T. Huang, Y. Hou, J. Chen, High-performance bi-functional electrocatalysts of 3D 512 crumpled graphene-cobalt oxide nanohybrids for oxygen reduction and evolution reactions, Energy \& 513 Environmental Science 7(2) (2014) 609-616.

514 [33] M. Fayette, A. Nelson, R.D. Robinson, Electrophoretic deposition improves catalytic performance of $515 \mathrm{Co} 3 \mathrm{O} 4$ nanoparticles for oxygen reduction/oxygen evolution reactions, Journal of Materials Chemistry A 3(8) (2015) 4274-4283.

517 [34] T. Zhang, C. He, F. Sun, Y. Ding, M. Wang, L. Peng, J. Wang, Y. Lin, Co3O4 nanoparticles anchored on nitrogen-doped reduced graphene oxide as a multifunctional catalyst for $\mathrm{H} 2 \mathrm{O} 2$ reduction, oxygen reduction and evolution reaction, Scientific Reports 7 (2017) 43638.

[35] S. Sui, L. Ma, Y. Zhai, TiC supported Pt-Ir electrocatalyst prepared by a plasma process for the oxygen electrode in unitized regenerative fuel cells, Journal of Power Sources 196(13) (2011) 5416-5422.

[36] R. Hahn, F. Schmidt-Stein, J. Salonen, S. Thiemann, Y. Song, J. Kunze, V.-P. Lehto, P. Schmuki, Semimetallic TiO2 Nanotubes, Angewandte Chemie International Edition 48(39) (2009) 7236-7239.

[37] W.S. Hummers, R.E. Offeman, Preparation of Graphitic Oxide, Journal of the American Chemical Society 80(6) (1958) 1339-1339.

[38] J. Flórez-Montaño, A. Calderón-Cárdenas, W. Lizcano-Valbuena, J.L. Rodríguez, E. Pastor, Ni@Pt nanodisks with low Pt content supported on reduced graphene oxide for methanol electrooxidation in alkaline media, International Journal of Hydrogen Energy 41(43) (2016) 19799-19809. and Co nanoparticles supported on electrospun carbon nanofibers as highly stable air electrodes, Journal of Power Sources 364(Supplement C) (2017) 101-109.

532 [40] C. Alegre, E. Modica, A.S. Aricò, V. Baglio, Bifunctional oxygen electrode based on a perovskite/carbon composite for electrochemical devices, Journal of Electroanalytical Chemistry (2017).

534 [41] R.D. McKerracher, C. Alegre, V. Baglio, A.S. Aricò, C. Ponce de León, F. Mornaghini, M. Rodlert, F.C. 535 Walsh, A nanostructured bifunctional Pd/C gas-diffusion electrode for metal-air batteries, Electrochimica Acta 536 174(Supplement C) (2015) 508-515.

537 [42] A. Kaniyoor, T.T. Baby, T. Arockiadoss, N. Rajalakshmi, S. Ramaprabhu, Wrinkled Graphenes: A Study on 538 the Effects of Synthesis Parameters on Exfoliation-Reduction of Graphite Oxide, The Journal of Physical 539 Chemistry C 115(36) (2011) 17660-17669.

540 [43] Y. Wu, S. Liu, H. Wang, X. Wang, X. Zhang, G. Jin, A novel solvothermal synthesis of Mn3O4/graphene 541 composites for supercapacitors, Electrochimica Acta 90(Supplement C) (2013) 210-218.

542 [44] K.N. Kudin, B. Ozbas, H.C. Schniepp, R.K. Prud'homme, I.A. Aksay, R. Car, Raman Spectra of Graphite 543 Oxide and Functionalized Graphene Sheets, Nano Letters 8(1) (2008) 36-41.

544 [45] Z.-H. Sheng, L. Shao, J.-J. Chen, W.-J. Bao, F.-B. Wang, X.-H. Xia, Catalyst-Free Synthesis of Nitrogen545 Doped Graphene via Thermal Annealing Graphite Oxide with Melamine and Its Excellent Electrocatalysis, 546 ACS Nano 5(6) (2011) 4350-4358. 

3D Graphene-Cobalt Oxide Electrode for High-Performance Supercapacitor and Enzymeless Glucose Detection, ACS Nano 6(4) (2012) 3206-3213.

[47] X. Wang, L. Song, H. Yang, W. Xing, H. Lu, Y. Hu, Cobalt oxide/graphene composite for highly efficient $\mathrm{CO}$ oxidation and its application in reducing the fire hazards of aliphatic polyesters, Journal of Materials Chemistry 22(8) (2012) 3426-3431.

553 [48] A.H.A. Monteverde Videla, P. Stelmachowski, G. Ercolino, S. Specchia, Benchmark comparison of Co3O4 spinel-structured oxides with different morphologies for oxygen evolution reaction under alkaline conditions, Journal of Applied Electrochemistry 47(3) (2017) 295-304.

[49] Z.S. Khalifa, Grain size reduction on nanostructured $\mathrm{TiO} 2$ thin films due to annealing, RSC Advances 7(48) 557 (2017) 30295-30302.

[50] M.V. Martínez-Huerta, J.L.G. Fierro, M.A. Bañares, Monitoring the states of vanadium oxide during the transformation of $\mathrm{TiO} 2$ anatase-to-rutile under reactive environments: $\mathrm{H} 2$ reduction and oxidative dehydrogenation of ethane, Catalysis Communications 11(1) (2009) 15-19.

561 [51] R. Boppella, J.-E. Lee, F.M. Mota, J.Y. Kim, Z. Feng, D.H. Kim, Composite hollow nanostructures composed of carbon-coated $\mathrm{Ti3}+$ self-doped $\mathrm{TiO} 2$-reduced graphene oxide as an efficient electrocatalyst for oxygen reduction, Journal of Materials Chemistry A 5(15) (2017) 7072-7080.

[52] M.P.S. D.Briggs, in:, M.P.S.E. D.Briggs, Practical Surface Analysis by Auger and X-Ray Photoelectron Spectroscopy, Wiley, New York (1990).

[53] M. Roca-Ayats, G. García, M. Soler-Vicedo, E. Pastor, M.J. Lázaro, M.V. Martínez-Huerta, The role of Sn,

$\mathrm{Ru}$ and Ir on the ethanol electrooxidation on Pt3M/TiCN electrocatalysts, International Journal of Hydrogen Energy 40(42) (2015) 14519-14528.

[54] G. Fu, P. Zhou, M. Zhao, W. Zhu, S. Yan, T. Yu, Z. Zou, Carbon coating stabilized Ti3+-doped TiO2 for 570 photocatalytic hydrogen generation under visible light irradiation, Dalton Transactions 44(28) (2015) 1281212817.

[55] P. Chen, F. Yang, A. Kostka, W. Xia, Interaction of Cobalt Nanoparticles with Oxygen- and NitrogenFunctionalized Carbon Nanotubes and Impact on Nitrobenzene Hydrogenation Catalysis, ACS Catalysis 4(5) (2014) 1478-1486.

[56] Y. Chen, S. Jie, C. Yang, Z. Liu, Active and efficient Co-N/C catalysts derived from cobalt porphyrin for selective oxidation of alkylaromatics, Applied Surface Science 419(Supplement C) (2017) 98-106.

[57] G. Wu, Z. Chen, K. Artyushkova, F.H. Garzon, P. Zelenay, Polyaniline-derived Non-Precious Catalyst for the Polymer Electrolyte Fuel Cell Cathode, ECS Transactions 16(2) (2008) 159-170.

[58] S. Bala, I. Mondal, A. Goswami, U. Pal, R. Mondal, Co-MOF as a sacrificial template: manifesting a new $580 \mathrm{Co3O} 4 / \mathrm{TiO} 2$ system with a p-n heterojunction for photocatalytic hydrogen evolution, Journal of Materials 581 Chemistry A 3(40) (2015) 20288-20296.

582 [59] G. Wu, K.L. More, C.M. Johnston, P. Zelenay, High-Performance Electrocatalysts for Oxygen Reduction 583 Derived from Polyaniline, Iron, and Cobalt, Science 332(6028) (2011) 443-447.

584 [60] L. Osmieri, A.H.A. Monteverde Videla, P. Ocón, S. Specchia, Kinetics of Oxygen Electroreduction on Me$585 \mathrm{~N}-\mathrm{C}(\mathrm{Me}=\mathrm{Fe}, \mathrm{Co}, \mathrm{Cu})$ Catalysts in Acidic Medium: Insights on the Effect of the Transition Metal, The Journal 586 of Physical Chemistry C 121(33) (2017) 17796-17817.

587 [61] A.J. Bard, L.R. Faulkner, ELECTROCHEMICAL METHODS: Fundamentals and Applications, JOHN 588 WILEY \& SONS, INC. (2001). 
589 [62] R. Chen, H. Li, D. Chu, G. Wang, Unraveling Oxygen Reduction Reaction Mechanisms on Carbon-

590 Supported Fe-Phthalocyanine and Co-Phthalocyanine Catalysts in Alkaline Solutions, The Journal of Physical

591 Chemistry C 113(48) (2009) 20689-20697.

592 [63] P. Singh, D.A. Buttry, Comparison of Oxygen Reduction Reaction at Silver Nanoparticles and

593 Polycrystalline Silver Electrodes in Alkaline Solution, The Journal of Physical Chemistry C 116(19) (2012)

594 10656-10663.

595 [64] S. Hebié, M. Bayo-Bangoura, K. Bayo, K. Servat, C. Morais, T.W. Napporn, K. Boniface Kokoh,

596 Electrocatalytic activity of carbon-supported metallophthalocyanine catalysts toward oxygen reduction

597 reaction in alkaline solution, Journal of Solid State Electrochemistry 20(4) (2016) 931-942.

598 [65] J. Zhang, H. Li, P. Guo, H. Ma, X.S. Zhao, Rational design of graphitic carbon based nanostructures for

599 advanced electrocatalysis, Journal of Materials Chemistry A 4(22) (2016) 8497-8511.

600 [66] X.B. Liu, I.S. Amiinu, S.J. Liu, K. Cheng, S.C. Mu, Transition metal/nitrogen dual-doped mesoporous

601 graphene-like carbon nanosheets for the oxygen reduction and evolution reactions, Nanoscale 8(27) (2016)

602 13311-13320.

603 [67] D. Deng, X. Pan, L. Yu, Y. Cui, Y. Jiang, J. Qi, W.-X. Li, Q. Fu, X. Ma, Q. Xue, G. Sun, X. Bao, Toward N-

604 Doped Graphene via Solvothermal Synthesis, Chemistry of Materials 23(5) (2011) 1188-1193.

605 [68] D. Guo, R. Shibuya, C. Akiba, S. Saji, T. Kondo, J. Nakamura, Active sites of nitrogen-doped carbon 606 materials for oxygen reduction reaction clarified using model catalysts, Science 351(6271) (2016) 361-365.

607 [69] Y. Liang, Y. Li, H. Wang, J. Zhou, J. Wang, T. Regier, H. Dai, Co3O4 nanocrystals on graphene as a 608 synergistic catalyst for oxygen reduction reaction, Nat Mater 10(10) (2011) 780-786.

609 